\title{
Cannibalism, post-settlement growth rate and size refuge in a recruitment-limited population of the shore crab Carcinus maenas
}

\author{
Maria João Almeida a , Juan Ignácio González-Gordillo ${ }^{\mathrm{b}}$, Augusto A.V. Flores ${ }^{\mathrm{c}}$, Henrique Queiroga ${ }^{\mathrm{a}, *}$ \\ a CESAM - Centro de Estudos do Ambiente e do Mar, Departamento de Biologia, Universidade de Aveiro, Campus Universitário de Santiago, $3810-193$ Aveiro, Portugal \\ b Centro Andaluz de Ciencia y Tecnologia Marina, Campus de Puerto Real, Universidad de Cádiz, E-11510 Puerto Real (Cádiz), Spain \\ c Centro de Biologia Marinha, Universidade de São Paulo, Rod. Manoel Hipólito do Rego, km 131.5, SP, Brazil
}

\section{A R T I C L E I N F O}

\section{Article history:}

Received 5 January 2011

Received in revised form 30 September 2011

Accepted 10 October 2011

Available online 1 November 2011

\section{Keywords:}

Habitat structure

Juvenile growth

Nursery habitat

Predation

Relative prey size

Shore crab

\begin{abstract}
A B S T R A C T
Previous studies on intra-specific interactions among green shore crabs have been undertaken in very large populations, in which individuals concentrate at high densities in physically complex substrates. Under such conditions, cannibalism and interference competition often override initial density patterns delivered by larval supply. In this study, we focused on a Carcinus maenas population receiving a low supply of settlers. We reported crab abundance in habitats of different physical structure, and measured cannibalistic interactions, in different substrates, at a prey density expected only after a major recruitment event. Different predator and prey sizes were used to verify if juveniles from a critical range attain a size refuge when coexisting with subadults, which are still commonly found in the nursery habitat. Virtually no juvenile shore crabs were found on sandy habitats, and differences between sparsely and densely vegetated cover were only detected shortly after a settlement pulse, indicating that nursery habitats are under their carrying capacity most of the time. Even under extreme high densities, cannibalism on juveniles of $10 \mathrm{~mm}$ carapace width (CW) remained undetected, and predation on crabs half this size was only significant in low and medium Zostera cover, when larger predators (20-25 mm CW) were included in experimental plots. The allometric model predicted the non-linear decrease of predation rate as a function of relative prey size, with a nearly asymptotic value of one prey consumed each $5 \mathrm{~d}$ by one predator in a square metre, when relative prey size attains 0.6 . Such a relationship is expected for 'cruising' predators which rely on encounter rate. Growth estimates obtained using time series of the catch of distinct juvenile stages in artificial collectors indicated that crabs surviving $50 \mathrm{~d}$ after settlement have attained a size refuge from predation by larger conspecifics.
\end{abstract}

(c) 2011 Elsevier B.V. All rights reserved.

\section{Introduction}

The green shore crab Carcinus maenas (L.) is a major benthic component along coastal habitats in Europe, and has recently invaded many temperate shorelines around the globe (Roman and Palumbi, 2004). This fast spread may well be a result of this species capacity to acclimate in salinity conditions ranging from fully marine to brackish mesohaline waters (Broekhuysen, 1936; Thomas et al., 1981), allowing the establishment of large populations from estuarine to open coast habitats, both at the intertidal and shallow subtidal. This species is particularly abundant in lower estuaries where it prevails. Different microhabitats can be successfully colonised by this species, but large densities are observed in biogenic substrates providing a complex physical structure, mainly seagrass meadows, mussel beds and gravel (Klein Breteler, 1975a; Moksnes et al., 1998; Zeng et al.,

\footnotetext{
* Corresponding author. Tel.: + 351234370 787; fax: + 351234372587. E-mail addresses: joaoalmeida@ua.pt (M.J. Almeida),nacho.gonzalez@uca.es (J.I. González-Gordillo), guca@usp.br (A.A.V.Flores), henrique.queiroga@ua.pt (H. Queiroga).
}

1999). Such distribution patterns are a result of several processes, taking place at different ontogenetic stages. Megalopae actively select vegetated substrates over bare sediments (Hedvall et al., 1998), but habitat-dependent predation (Moksnes et al., 1998) and crab movements (Moksnes, 2004a), which range increases with crab size (Almeida et al., 2008), modify initial occupation patterns.

Coastal brachyuran crabs concentrate in substrate patches where interstitial spaces, scaled to their size, are abundant (Beck, 1995; Casariego, et al., 2004; Flores and Negreiros-Fransozo, 1999). Juveniles of the green shore crab may remain within the boundaries of such nursery areas for several weeks to a few months, and the strength of intra-specific interactions increases as crabs aggregate at these areas during the recruitment season (Klein Breteler, 1975a; Moksnes, 2004b; Moksnes et al., 1998). Because cannibalism is quite frequent in $C$. maenas and size-structured populations develop over that time, very marked density-dependent regulation is expected to be common. First crab instars and sub-adults may coexist in small nursery patches, leading to potential relative prey sizes smaller than 10\% (Almeida et al., 2008; Silva et al., 2006), thus favouring cannibalistic interactions. The extent to which these different cohorts can coexist is 
therefore a crucial variable determining the persistence and stability of shore crab populations.

Several studies have focused demographic aspects of the green shore crab around the world, mostly within its native geographical range. Environmental variability along the Atlantic European coast varies substantially at different geographical scales, including the advective potential of coastal waters (e.g. Coelho et al., 2002; Holt and Proctor, 2003; Otto et al., 1990) and the relative cover of biogenic complex substrates in intertidal and shallow-water estuarine areas (Airoldi and Beck, 2007), which are important ecosystem features controlling the size and density of $C$. maenas populations. As a result, population parameters may change dramatically at different spatial scales. Within a few hundreds of kilometres, larval supply and settlement rates vary over 1-2 orders of magnitude over the western coast of Portugal (Almeida and Queiroga, 2003; Queiroga et al., 2006). Lowest values along the Portuguese Atlantic are close to settlement rates measured in Nova Scotia, Canada (Cameron and Metaxas, 2005), where C. maenas has been introduced, but highest ones are likely to fall short compared to estuarine reaches in Sweden, where structured grounds may hold juvenile densities up to 500 ind. $\mathrm{m}^{-2}$ (Moksnes, 2002). Most research on post-settlement processes regulating shore crab populations was undertaken in the Gullmarsfjord, Sweden, where juvenile recruitment to the intertidal area is very high and post-settlement processes are major determinants of population regulation. Initial crab stages are readily consumed by larger juveniles, even when seagrass is available (Moksnes et al., 1998), up to a point that settling cohorts can be entirely decimated (Moksnes, 2004b). Predation rate drops exponentially as prey size increases, from an almost $70 \%$ loss in the first $24 \mathrm{~h}$ for recently settled prey, to less than $10 \%$ in juveniles ranging from 5.0 to $9.0 \mathrm{~mm}$ carapace width (CW) and beyond (Moksnes et al., 1998). Yet, the size at which crabs attain a refuge from predation remains a matter of concern. In this same study, the authors have found that, later in the season, crabs between 5.0 and $9.0 \mathrm{~mm}$ can still be consumed by juvenile cohorts that settled earlier and have already grown to a predator size. In these stages, there is still a reduced mortality risk in seagrass meadows compared to sand bottoms.

Considering previous estimates of megalopal supply and settlement rate, shore crab populations are likely to be recruitmentlimited at the Ria de Aveiro, Portugal, and the density of juveniles at nursery areas is expected to be much lower. In this scenario, the strength of cannibalistic interactions would be much reduced. In this study, we measured the extent to which juveniles in a critical size range are predated by larger conspecifics. Different predator sizes within the limits found in our study area were tested, providing an array of relative prey sizes from 0.20 to 0.67 (prey size/predator size), and survival was examined among substrates of different complexity. This experiment allowed us to test whether there is a sizerefuge from predators within nursery areas and whether predictions from past studies can be applied in the apparently recruitmentlimited system at the Ria de Aveiro. In addition, the time these crabs take to grow to an eventual refuge size was estimated using timeseries analyses of the frequency of different juvenile stages on artificial collectors, deployed in the field. Because there is a positive relationship between temperature and growth rate in crustaceans (Hartnoll, 2001), we expected that juveniles in the Portuguese Atlantic coast would grow at a higher rate than its northern Europe counterparts, and, therefore, the time they are exposed to a major predation risk would be reduced.

\section{Methods}

\subsection{Study area and sampling sites}

This study was conducted in the Canal de Mira, Ria de Aveiro. Ria de Aveiro is a bar-built estuary located on the northwest coast of Portugal $\left(40^{\circ} 38^{\prime} \mathrm{N} ; 8^{\circ} 46^{\prime} \mathrm{W}\right)$. Tides in the Ria de Aveiro, which are the main factor influencing circulation within the estuary, are semidiurnal, with a mean tidal range of $2.1 \mathrm{~m}$ at the inlet. Canal de Mira is one of the branches of the Ria de Aveiro and can be considered a small estuary in itself with a full salinity gradient (Dias et al., 2003). With a maximum width of $1 \mathrm{~km}$ and an average depth of $3 \mathrm{~m}$, it evolves from the inlet towards the southeast, parallel to the coastline, for an approximate extension of $20 \mathrm{~km}$. Canal de Mira is margined by large intertidal mudflats and seagrass beds that provide suitable conditions for settlement of $C$. maenas megalopae and that are used as a feeding ground for both juvenile and adult crabs (Almeida and Queiroga, 2003).

Experiments on juvenile densities and growth rates took place during the spring and early summer of 2002 in three different intertidal habitat types with decreasing degrees of structural complexity: i) typical seagrass beds dominated by Zostera noltii (Zostera), ii) muddy sediments with a sparse cover of algae and shells (Mixed), and iii) unvegetated sandy habitat (Sand). These three types of habitats were distributed in a downstream (Site 1) and in an upstream (Site 2) site (Fig. 1). Experiments on cannibalism were conducted in cages deployed in the intertidal where densities and sizes of prey and predators, as well as substrate complexity, were manipulated.

\subsection{Temporal recruitment patterns and juvenile growth rate}

Artificial substrate collectors $(50 \times 40 \mathrm{~cm})$, made of 'hoghair' filter material, were used to obtain daily time series of megalopae settlement and juvenile abundance at both the Zostera and mixed cover of Site 1 (Fig. 1), from April 3 to July 25, 2002. Five collectors were haphazardly deployed, a few metres apart, over the bottom at each habitat type and replaced daily at diurnal low tide. In the laboratory, collectors were washed in freshwater, and the rinsed water was filtered through a $0.5 \mathrm{~mm}$ sieve to retain all specimens. The carapace width (CW, measured between the tips of lateral spines) of all megalopae and juveniles was measured with an ocular micrometric to the nearest $0.1 \mathrm{~mm}$.

Over the sampling period, 221 megalopae and 1645 juveniles were collected. A random subsample of 115 juveniles was used for determination of stage and sex. An identification key adapted from Shen (1935) was used to define juvenile stages according to size and shape of the endopodites and exopodites of the pleopods. Within this subsample, the CW of juveniles ranged from 1.35 to $14.0 \mathrm{~mm}$ and seven juvenile stages were identified. The remaining juveniles were then assigned to each instar based on their size. This analysis showed there was no size overlap between successive juvenile stages up to instar 5. Instars 5 and 6 had an overlapping region of about $1 \mathrm{~mm}$ and instars 6 and 7 of $3 \mathrm{~mm}$. However, this analysis indicated that instar 3 was strongly bimodal, suggesting a moult without noticeable morphological changes in the abdominal appendages. Therefore, a second estimate for size intervals of first juvenile instars was obtained by decomposing the overall size frequency distribution into normal components, using a size class of $0.2 \mathrm{~mm}$ and assuming these groups coincide with the initial instar sequence. Modal groups were discriminated using the Bhattacharya (1967) method and attributed to crab instars only when separation indices were equal or higher than 2.0 (Fig. 2). This routine was accomplished using the software package FiSAT II (FAO-ICLARM Fish Stock Assessment Tools). Instar size ranges inferred by the examination of pleopods and by decomposing the overall size frequency distribution into modal groups provided remarkably similar results, except for instars 3 and 4 . This strongly suggests that, unlike laboratory-held individuals reared by Shen (1935), green crab juveniles at the Ria de Aveiro had moulted from the 3rd to 4th stage without any noticeable morphological change. We therefore used the instar size limits estimated by the morphological method in the subsequent analyses, except for instars 3 and 4 where the estimates from the Bhattacharya method were used. 


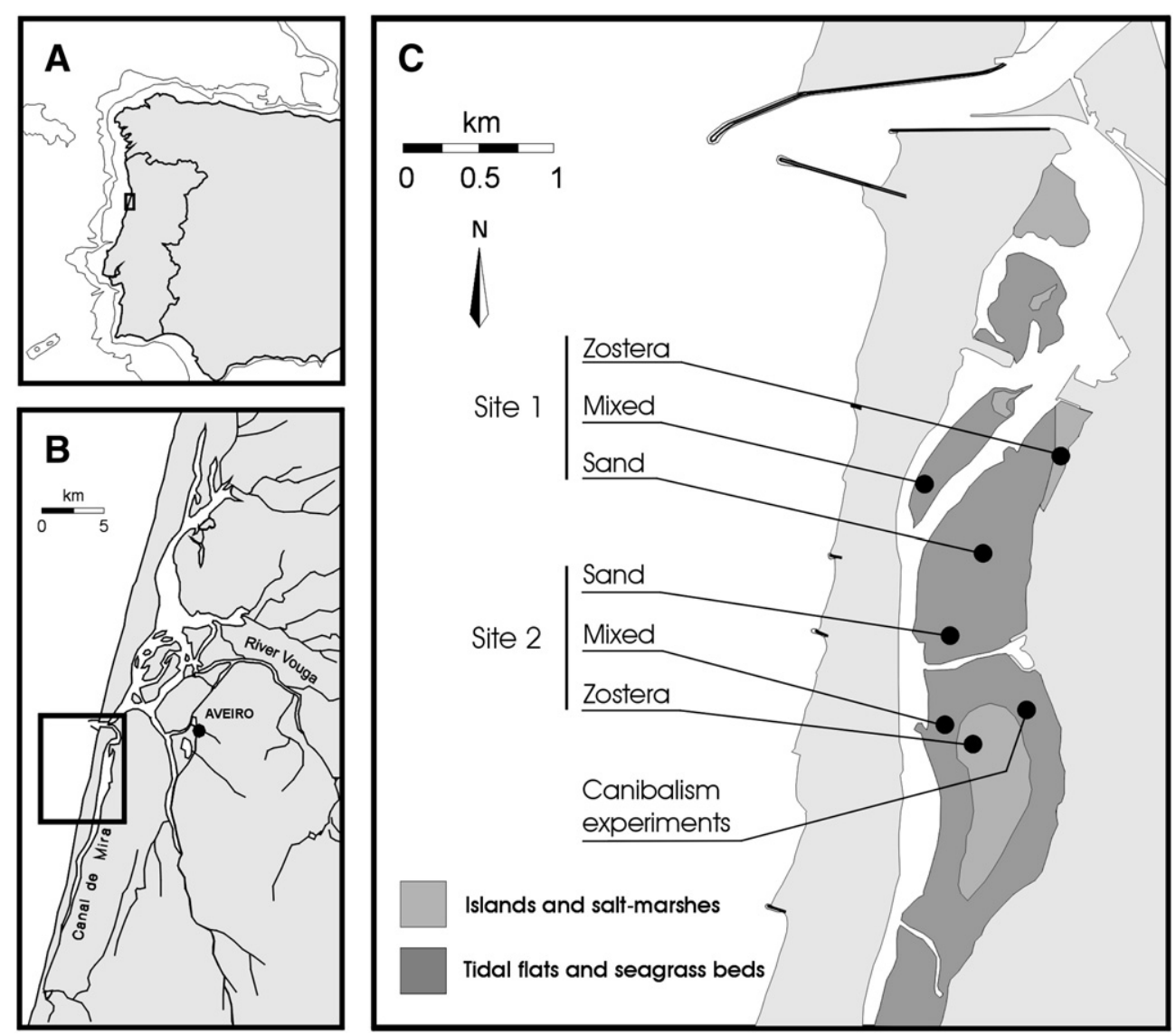

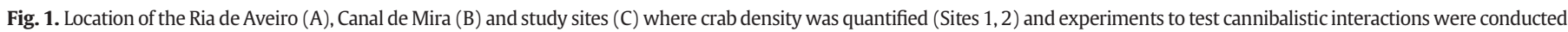

In order to estimate time lags between successive juvenile instars we used lagged cross-correlation analysis between time series of abundance of each instar, after smoothing the trend with a 5-d moving average. Since the time series of abundance were significantly autocorrelated at a time lag of $1 \mathrm{~d}$, the series were differentiated at this time lag. Because instars 1 to 7 showed only a modest overlap, juveniles

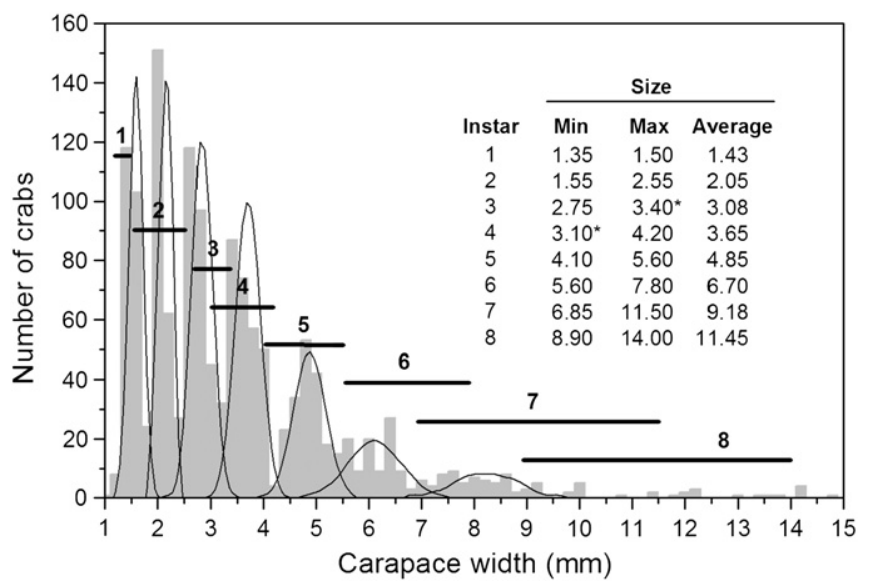

Fig. 2. Carcinus maenas. Size frequency distribution of juveniles obtained in substrate collectors deployed at Site 1, over the time series obtained to estimate juvenile growth rates. Thin lines represent normal components discriminated using the Bhathacharya method. Horizontal bars show the size intervals of juvenile instars based on morphological analyses of a random subsample of 115 individuals, except for the upper boundary of instar 3 and lower boundary of instar 4, indicated by asterisks, which derived from the inspection of normal curves. The occurrence of four individuals larger than $15.0 \mathrm{~mm} \mathrm{CW}$ is not shown. were ascribed to each of these instars based on the average size of the overlapping range. Instars 7 and 8 were pooled together. We interpret the time lags between abundance patterns of successive instars given as the duration of instars. The growth rates of each instar were then estimated by dividing the instar average size increment by the duration of the instar.

\subsection{Crab densities at the study area}

Because there was no prior information on the density and distribution patterns of $C$. maenas in this study area, we used sediment sampling to estimate crab abundances at the most representative microhabitats. These estimates allowed us to set up the predation experiment (below) under realistic conditions. Ten $50 \times 50 \mathrm{~cm}$ quadrats, separated by a few metres, were randomly assigned at the Zostera, mixed and sand areas at sampling sites 1 and 2, during two sampling dates (June 14 and July 26). Inside each quadrat, the 2-cm superficial layer of sediment was removed and preserved in $40 \%$ formalin for later sorting. We assumed that sediment sampling accurately measures the density of juvenile crabs, regardless of habitat complexity. The sand habitat was excluded from statistical analyses because crabs were nearly absent in samples.

Differences on crab densities were examined through a specific ANOVA model, in which Habitat is a fixed factor with two levels (Zostera and mixed), orthogonal to the random factor Date (two levels, $6 / 14,7 / 26$ ), to verify whether habitat use is coherent through time. An additional random level, Site (two levels, sites 1 and 2), was nested in the combination of Habitat and Date, to verify whether there is a spatial effect at the scale of hundreds of metres blurring any habitat differences. Variances were homogeneous (Cochran's $C=0.3832$; $p>0.05$ ) and therefore raw data were used in this analysis. 


\subsection{Cannibalism rates according to size and habitat complexity}

Cannibalism rates on different combinations of prey size, predator size and substratum cover were compared using cages deployed in an area of the Canal de Mira, devoid of vegetation and with a sandy bottom with shells (Fig. 1), in the early summer of 2003. Cages were constructed with a wire frame $(50 \times 50 \times 10 \mathrm{~cm})$, which supported a plastic mesh to prevent juveniles to escape or intruders to enter. Care was taken to bury an extension of the lower rim of the plastic net into the sediment in order to avoid crabs or other mobile organisms to enter or escape the cage. Before setting up the cages, the sediment was carefully cleaned to ensure that there were no crabs buried inside. While cages were being prepared, shore crabs were hand captured in nearby nursery areas. These specimens were sorted according to predefined size classes and put in aerated buckets until the beginning of the experiments. We tested 2 sizes of prey juveniles: small prey, ca. $5 \mathrm{~mm} \mathrm{CW}$, corresponding to juvenile instars 3 and 4, and large prey near $10 \mathrm{~mm}$ CW, corresponding to juvenile instars 5-7 (Almeida et al., 2008). Three different predator sizes were tested: $15 \mathrm{~mm}, 20 \mathrm{~mm}$ and $25 \mathrm{~mm}$ CW. We also used cages without predators as a control treatment.

The influence of refuge complexity in cannibalism rate was tested by using patches of $Z$. noltii that were transplanted from a nearby seagrass bed to the interior of the cages. We tested 3 densities of $Z$. Noltii; low (5\%), medium (20\%) and high (75\% cover), and included 5 prey and 1 predator in all cages. Therefore, a constant crab density of 24 ind $\mathrm{m}^{-2}$ was used in this experiment. Based on our own measurements (see results), this is close to density values shortly after a recruitment pulse. When all the experimental conditions inside the cages were set up, the top of the cage was closed. Mortality was assessed after $72 \mathrm{~h}$ and each experimental condition was replicated 3 times.

Mortality was tested as the dependent variable in a Generalised Linear Model (GLM) where Refuge (three levels: low, medium and high density of Zostera), Prey size (two levels: $5 \mathrm{~mm}$ and $10 \mathrm{~mm}$ $\mathrm{CW}$ ) and Predator size (four levels: no predator $=$ control, $15 \mathrm{~mm}$, $20 \mathrm{~mm}$ and $25 \mathrm{~mm} \mathrm{CW}$ ) were orthogonal factors. Because mortality was measured as counts of dead prey a Poisson distribution of the residuals was assumed and a logarithmic link function used to model the relationship of mortality with the predictor variables (Quinn and Keough, 2002).

We used the data obtained in substrate conditions where cannibalism is indeed significant (see Results) to predict predation rate (PR; crabs consumed predator ${ }^{-1} \mathrm{~d}^{-1} \mathrm{~m}^{-2}$ ) given the relative prey size (RPS; prey size/predator size). For that, we used the allometric model,

$P R=a \times R P S^{b}$

based on well-known relationships described for piscivore predatorprey interactions, regulating recruitment of the preyed species (Bailey and Houde, 1989; Paradis et al., 1996; Scharf et al., 1998).

\section{Results}

\subsection{Temporal recruitment patterns and juvenile growth rates}

The size frequency distribution of all crabs collected during the entire time series, together with minimum, maximum and average size of the first seven crab stages, identified in a sub-sample of 115 individuals, is shown in Fig. 2. As expected, size range increased from the early to late stages, probably due to variation of growth rates among individuals. Because we sampled during the settlement season, the overall size distribution is strongly skewed to the right. Natural distributions should have been even more asymmetric, because collectors select larger crabs, with increased walking range (Almeida et al.,
2008). Average growth increment at moult was relatively high (35.0\%), in accordance to what was verified in other portunids, generally decreasing from early to late stages, with a maximum value for crabs moulting to instar 3 (50.0\%), and a minimum value for those moulting to instar 8 (24.7\%), following the general pattern expected for decapod crustaceans (Hartnoll, 1982).

The catch of megalopae and juvenile instars throughout the sampling period is illustrated in Fig. 3. Megalopae settlement was highly episodic with peaks that appear to be followed, almost immediately, by an increase of the catch of first juvenile instars. Settlement events of megalopae that occurred during the first two weeks of April, can be corresponded to increases in abundance of instars 1,2 and 3 that occurred, respectively, during the second and third weeks of April, mid to end of April, and third week of April to mid May. A similar pattern can be noticed for megalopae settled during the third and fourth weeks of May, and from the last week of June onwards. Despite of less clear temporal patterns for stages $4-7$, cross-correlations between successive stages were significant in all cases, except for instar 1 vs instar 2 (Table 1 ).

Duration of each instar averaged 1 week, ranging from $3 \mathrm{~d}$ in the megalopa to $15 \mathrm{~d}$ in instar 4 (Table 1 ). Growth rates ranged from $0.09 \mathrm{~mm} \mathrm{~d}^{-1}$ in instar 2 to $0.28 \mathrm{~mm} \mathrm{~d}^{-1}$ in instar 6 . Total time to reach instar 6 was $41 \mathrm{~d}$, which lies between the $31 \mathrm{~d}$ and $69 \mathrm{~d}$ estimates by Klein Breteler (1975b) and Shen (1935), respectively (Table 1). Average increment at moulting in our study was $45.5 \%$, which was considerably larger than mean increments observed by Klein-Breteler (38.0\%) and Shen (28.0\%). As a result, size at the 6th juvenile instar in the natural population at Ria de Aveiro was 17.1 and $47.8 \%$ larger than laboratory reared specimens in the above studies.

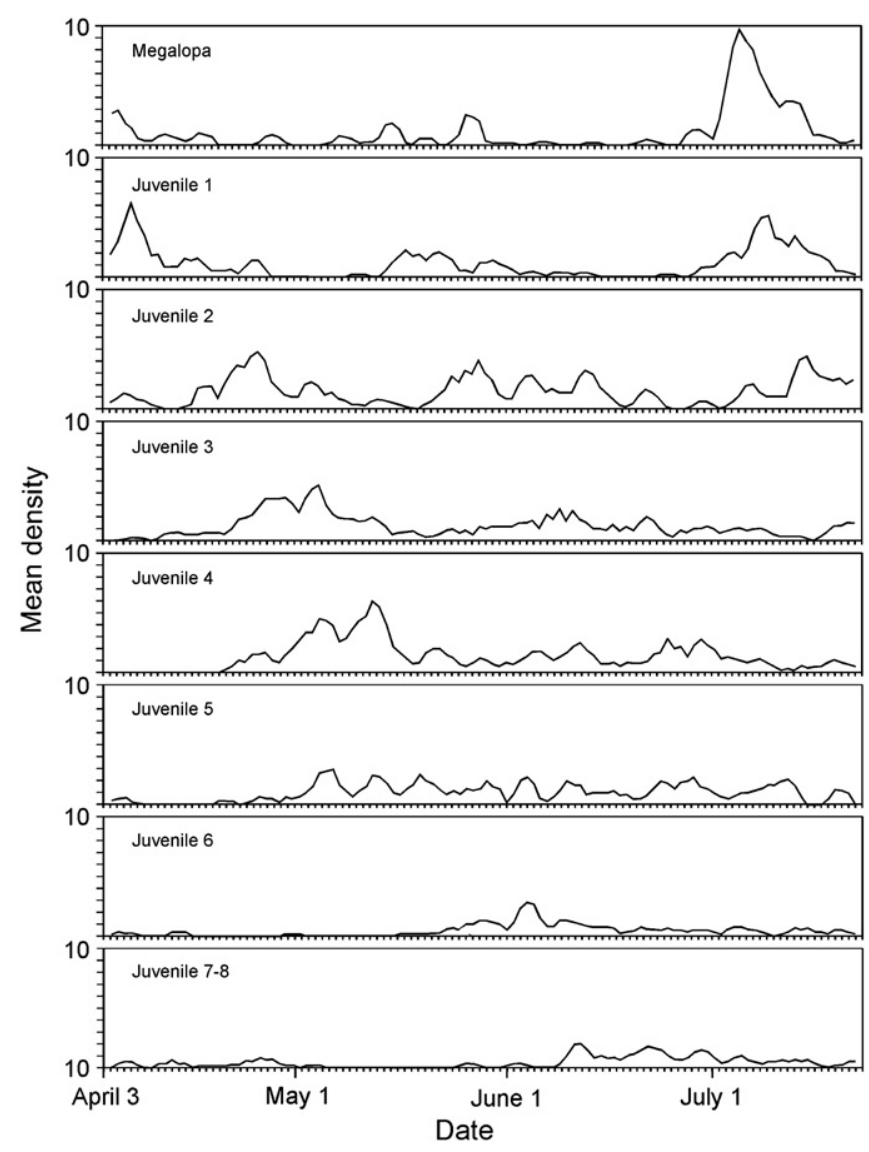

Fig. 3. Carcinus maenas. Mean daily densities per collector of megalopae, instars 1, 2, 3, 4,5 and $6-7$. 
Table 1

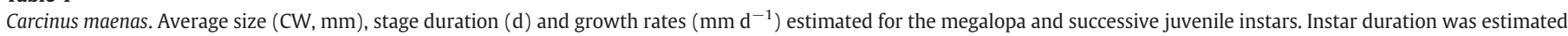

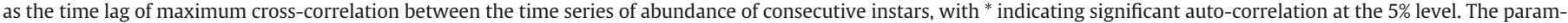

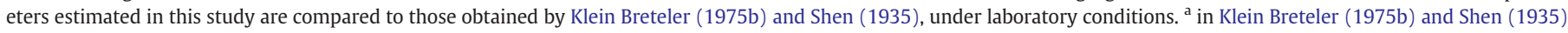
indicates juvenile instar 7.

\begin{tabular}{|c|c|c|c|c|c|c|c|c|c|}
\hline \multirow[t]{2}{*}{ Instar } & \multicolumn{3}{|c|}{ This study } & \multicolumn{3}{|c|}{ Klein Breteler (1975b) } & \multicolumn{3}{|c|}{ Shen (1935) } \\
\hline & Size & Duration & Growth rate & Size & Duration & Growth rate & Size & Duration & Growth rate \\
\hline Meg & 1.05 & $4^{*}$ & 0.10 & - & - & - & - & - & - \\
\hline Juv 1 & 1.43 & $6^{\mathrm{ns}}$ & - & 1.50 & 4 & - & 1.90 & 7 & - \\
\hline Juv 2 & 2.05 & $8^{*}$ & 0.13 & 2.10 & 6 & 0.15 & 2.36 & 12 & 0.07 \\
\hline Juv 3 & 3.08 & $8^{*}$ & 0.07 & 2.89 & 7 & 0.13 & 3.01 & 14 & 0.05 \\
\hline Juv 4 & 3.65 & $6^{\text {ns }}$ & - & 3.98 & 6 & 0.16 & 3.75 & 18 & 0.05 \\
\hline Juv 5 & 4.85 & $7^{*}$ & 0.26 & 5.57 & 8 & 0.27 & 4.95 & 18 & 0.07 \\
\hline Juv 6 & 6.70 & $7^{*}$ & 0.35 & 7.84 & - & 0.28 & 6.21 & - & 0.07 \\
\hline Juv 7-8 & 9.94 & - & - & $10.33^{\mathrm{a}}$ & - & - & $8.32^{a}$ & - & - \\
\hline
\end{tabular}

\subsection{Crab densities at the study area}

Crab densities were quantified at two very different periods, the first coinciding with the lowest settlement rates recorded (July 14), and the second shortly after the major settlement event detected (July 26) (Fig. 3). As a result, overall crab densities were higher at the second sampling date, but this variation was not equivalent in mixed and Zostera patches, rendering a significant interaction between factors 'Habitat' and 'Date' (Table 2). At mixed plots, density was always low, from 2 to 4 ind $\mathrm{m}^{-2}$, but after a heavy settlement pulse, differences between habitats become clear, with density raising over 18 ind $\mathrm{m}^{-2}$ at Zostera (Fig. 4). Variation among sites, some hundreds of metres apart, was not significant.

\subsection{Cannibalism rates according to size and habitat complexity}

The cannibalistic response varied among different combinations of predator and prey sizes and also with respect to habitat complexity, with a significant triple interaction (refuge, prey and predator sizes, Table 3). Non-overlapping 95\% confidence intervals are usually taken as indication of significantly different means. Using this criterion, the treatments with small prey and predators of 20 and $25 \mathrm{~mm}$ CW differed from the control experiments in the cases of low and medium Zostera cover, respectively (Fig. 5). There was also a highly overall significant effect of predator size on predation rate (Table 3), so that larger predators were more effective in declining prey numbers than smaller ones.

These results suggest that juveniles reaching $10 \mathrm{~mm} \mathrm{CW}$ may be relatively safe from predation, and that relative prey size (RPS) may be an adequate predictor of predation rate (PR). Considering only the low and mid Zostera conditions, where cannibalism was detected, the allometric model provided an adequate relationship $(F=44.7$; $p<0.001$ ), with RPS explaining $58 \%$ of the variation of PR (Fig. 6). There is no apparent segregation of data obtained at medium and low Zostera cover, and PR decreased $78.4 \%$ over the RPS range examined (0.20-0.67). At an RPS of 0.6 , PR reaches the nearly asymptotic

\section{Table 2}

Carcinus maenas. Results of the ANOVA model comparing crab densities in two major habitat types (Zostera and mixed, see text), at two different random dates to test temporal consistency of spatial differences. Spatial variation at the hundreds of metres scale was tested by adding the factor 'Site', nested in the combination of 'Habitat' and 'Date'.

\begin{tabular}{lrrrl}
\hline Source of variation & df & \multicolumn{1}{c}{ MS } & \multicolumn{1}{c}{ F } & p \\
\hline Habitat & 1 & 846.4 & 1.32 & 0.456 \\
Date & 1 & 270.4 & 16.10 & 0.016 \\
Site (Habitat $\times$ Date) & 4 & 16.8 & 0.25 & 0.907 \\
Habitat $\times$ Date & 1 & 640.0 & 38.10 & 0.004 \\
Residual & 32 & 66.8 & & \\
\hline
\end{tabular}

value of 0.2 , i.e. one prey consumed each $5 \mathrm{~d}$ by one predator in a square metre.

\section{Discussion}

In agreement to early studies on the ecology of juvenile stages of the green shore crab, our results confirm that population size is partially regulated by the availability of structural complex habitats. Megalopae and first instar juveniles exhibit high plasticity in selecting habitats and exploring refuges among several heterogeneous substrates (Almeida ad Queiroga, 2003; Hedvall et al., 1998; Moksnes et al., 2003; Paula et al., 2006), and structured habitats are selected mainly because they provide shelter that prevents predation (Hedvall et al., 1998; Moksnes et al., 2003) and concentrate living and dead organic matter that may be used as food (Perkins-Visser et al., 1996). We report a nearly absence of crabs in sandy substrates, but in our study system dense vegetation cover not always sustained larger crab densities. Differences between Zostera and mixed substrates were only recorded after a major settlement pulse, when crab densities apparently exceeded the carrying capacity of the less structured habitat, favouring intra-specific regulation, either via cannibalism or migration. Supply of $C$. maenas larvae to the Ria de Aveiro is very low compared to other systems (Almeida and Queiroga, 2003; Queiroga et al., 2006) and the ability of the Zostera habitat to accommodate increased number of crabs after settlement events suggest that, most of the time, the shore crab population at the Ria de Aveiro is recruitment-limited. This should not be the case in most other areas where the density of juvenile $C$. maenas is orders of magnitude larger, as in the Mira estuary (Almeida et al., 2008) or the Ria Formosa (Sprung,

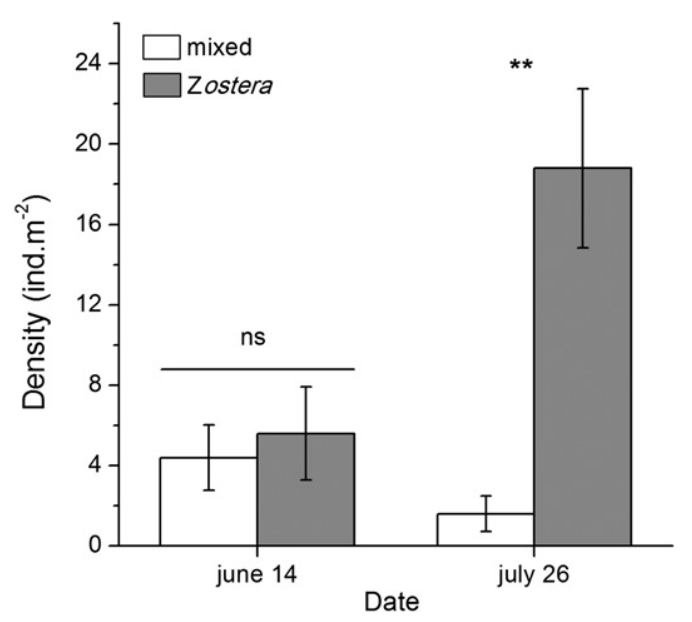

Fig. 4. Carcinus maenas. Average density $( \pm 1 \mathrm{SE})$ at mixed and Zostera patches at different sampling dates. ns: not significant; ${ }^{* *} \mathrm{p}<0.01$. 
Table 3

Carcinus maenas. Results of the Generalised Linear Model testing the effect of refuge (low, medium and high cover of Zostera), prey size ( $5 \mathrm{~mm}$ and $10 \mathrm{~mm} \mathrm{CW}$ ) and predator size (control, $15 \mathrm{~mm}, 20 \mathrm{~mm}$ and $25 \mathrm{~mm}$ CW) on prey mortality. Predators were not included in the control replicates.

\begin{tabular}{llcl}
\hline Source of variation & df & Chi-square & p \\
\hline Refuge & 2 & 4.387 & 0.112 \\
Prey size & 1 & 3.087 & 0.079 \\
Predator size & 3 & 26.585 & 0.000 \\
Refuge $\times$ Prey size & 2 & 0.131 & 0.937 \\
Refuge $\times$ Predator size & 6 & 3.374 & 0.761 \\
Prey size $\times$ Predator size & 3 & 0.397 & 0.941 \\
Refuge $\times$ Prey size $\times$ Predator size & 4 & 11.555 & 0.021 \\
\hline
\end{tabular}

2001) in Portugal, but especially in the Gullmarsfjord in Sweden (Moksnes, 2002).

We conducted our predation experiment at crab densities only expected after major settlement events. Even in such conditions, the carrying capacity of nursery habitats is likely to be above critical values. At $10 \mathrm{~mm} C W$, juveniles attain an apparent size refuge from predation, even in poorly structured substrates, and crabs half this size are already safe in dense Zostera patches, but still vulnerable at intermediate and low vegetation cover. Under conditions of shelter shortage, predation rate depended on size, with higher consumer rates by larger conspecifics, and no apparent response gradient from low to high cover. Therefore, a critical threshold, as observed for bivalve prey on vegetated habitats of varying complexity (Irlandi et al., 1995), should occur in our study system somewhere between 0 and $25 \%$ Zostera, suggesting that even very sparse vegetation cover can largely mitigate cannibalistic pressure. Within this narrow

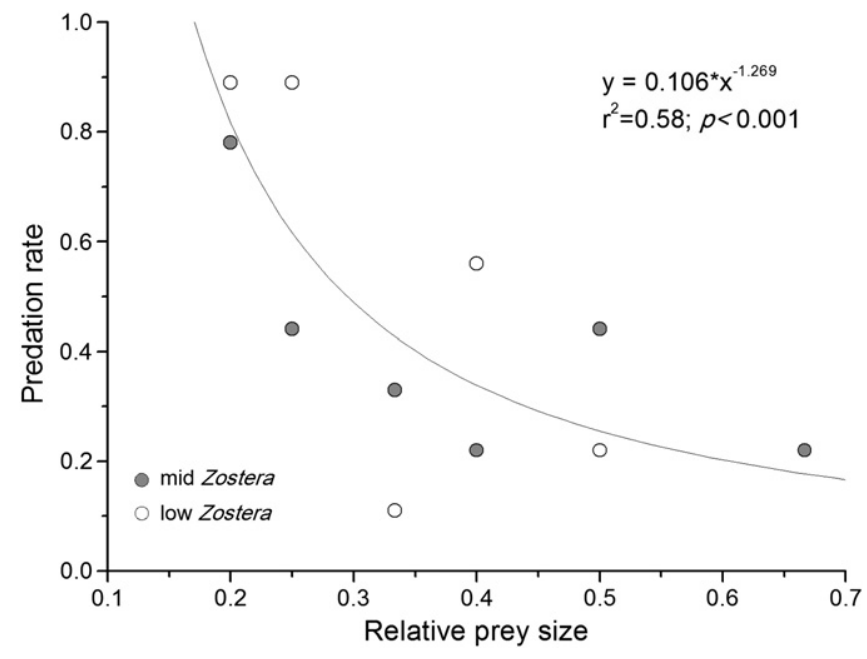

Fig. 6. Relationship between predation rate (crabs consumed predator ${ }^{-1} \mathrm{~d}^{-1} \mathrm{~m}^{-2}$ ) and relative prey size (Prey size/Predator size) using average numbers in experimental trials under mid (20\%) and low (5\%) Zostera cover.

range, predation rate (PR) is explained to a large extent (58\%) by the relative prey size (RPS) in a non-linear relationship, with PR dropping to nearly low asymptotic values when RPS approaches to 0.6. The decaying coefficient $(b=-1.269)$ is similar to what is found in systems where, in addition to size differences between prey and predators, the encounter rate is very important, such as the consumption of ichthyoplankton by medusae (Paradis et al., 1996). This seems a general model for cruising invertebrate predators (Bailey and
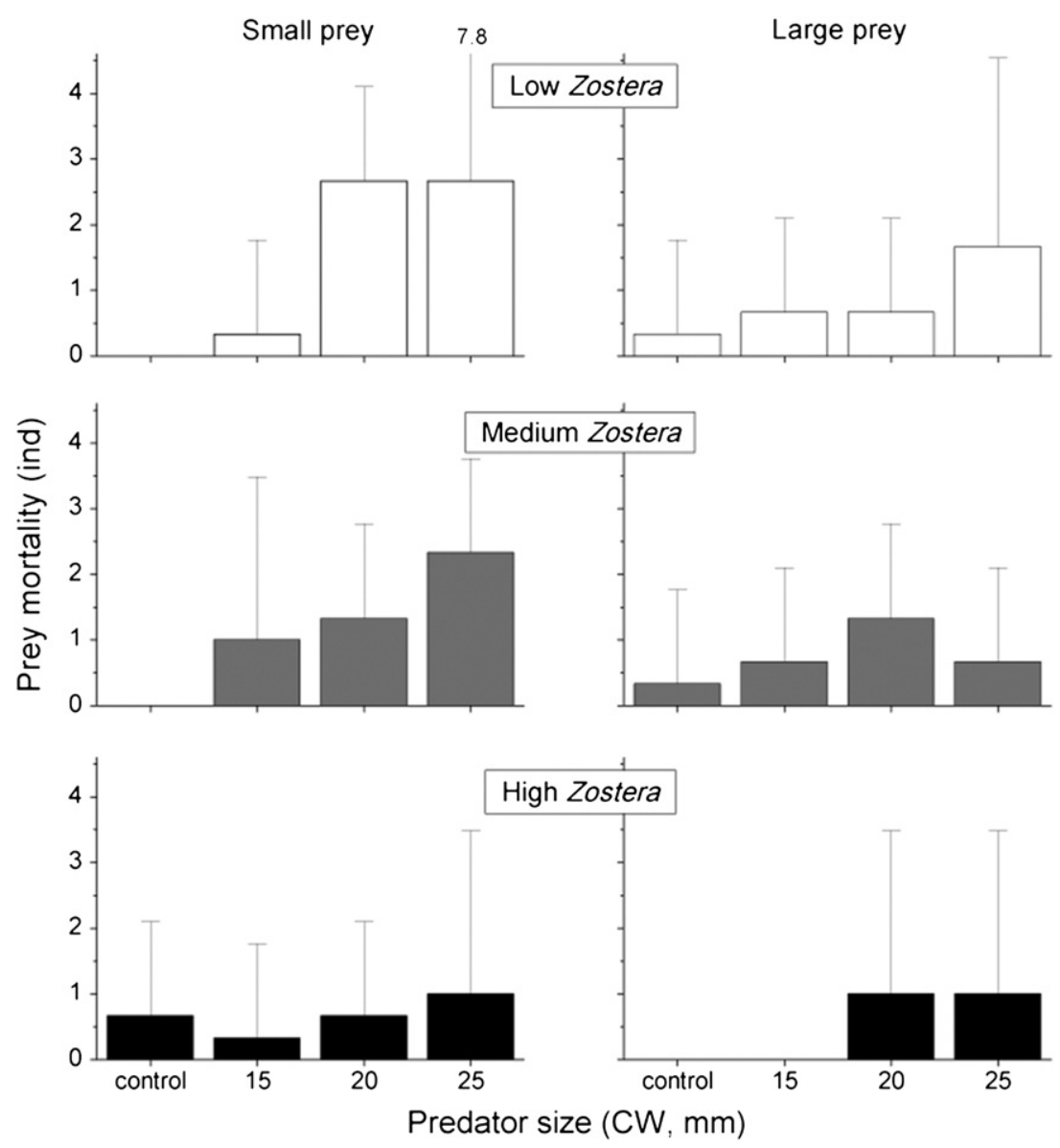

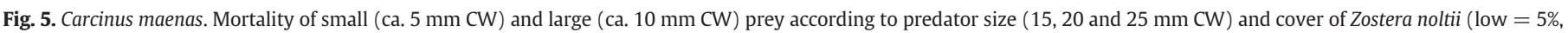

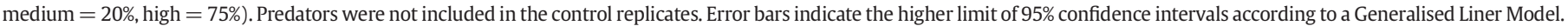


Houde, 1989). Therefore, one of the mechanisms to increase the carrying capacity of any given nursery habitat is to minimise the encounter rate between prey and predators. This seems to be a strategy adopted by $C$. maenas, because coexisting early recruits (mostly prey) and late juveniles (mostly predators) are active at different times over the diel cycle (Almeida et al., 2008).

In spite of a great deal of information on many aspects of $C$. maenas intra-specific interactions, (e.g. Moksnes, 2002, 2004a, 2004b) there is only marginal information on predation rates of juvenile and subadults, still using nursery habitats, on younger crabs within a size range at which predation pressure is expected to rapidly decrease. Moksnes (2004b) modelled the variation of predation rate as a function of prey density, using juvenile stages 6 to 7 ( 6.0 to $10.0 \mathrm{~mm} \mathrm{CW}$ ) on first stage recruits ( $1.5 \mathrm{~mm} \mathrm{CW}$ ), that is, a RPS of 0.19 . At the densities found in the Ria de Aveiro, the predicted predation strength using that model is 0.13 . Using the RPS vs. PR relationship obtained in the present study, we would expect a predation impact larger than 1.0. This difference is likely due to the difficulty of handling very small prey (ap Rheinallt, 1986; Rangeley and Thomas, 1987). Thus, unlike larger crabs close to a size refuge, which may be occasionally consumed by much larger conspecifics, most cannibalism on early settlers should be driven by slightly larger juveniles, as previously observed (Moksnes et al., 1998).

The time needed for early settlers to grow to a size at which predation by conspecifics is negligible is a critical parameter determining population dynamics in this species. However, growth rates from natural populations are difficult to estimate. Field mark-recapture methods, that could address this problem, are logistically complex and require time-consuming protocols. Very large numbers of individuals should be marked in order to allow recapture of sufficient numbers of crabs. In the case of small juveniles, the task is even more difficult because minute tags are required and their loss should be much higher due to frequent moulting. While microwire and elastomer tags can be used in blue crab juveniles larger than $6 \mathrm{~mm}$ CW (Davis et al., 2004), we are not aware of successful attempts in smaller crab stages. Another approach is to obtain size frequency distributions and track specific agegroups (Flores et al., 2002; Fukui, 1988). This technique requires sampling a very large number of individuals in order to separate normal components within polymodal distributions and is only possible if settlement pulses are sufficiently discrete to generate different cohorts. Due to these reasons, literature describing growth rates of $C$. maenas juveniles is rare and estimates were gathered in laboratory conditions (Klein Breteler, 1975b; Shen, 1935), which might be biassed due to unrealistic environmental conditions (Hartnoll, 1982; Klein Breteler, 1975a).

We explored the attraction of megalopae and juveniles to artificial collectors to obtain frequency time series of initial juvenile stages, and used cross-correlation analyses to assess their duration. Assuming that in a particular habitat the efficiency of collectors does not change over time, changes in abundance in the collectors should be proportional to changes in true abundance through time. Therefore, it should be possible to obtain a cost-effective measure of growth in natural conditions by inspecting the temporal differences between peaks of abundance of consecutive instars. This methodology would also be robust even if the efficiency of the collectors changed with size class, because relative changes of abundance in each class would still be present.

Our results indicated that juvenile instars reach $5.0 \mathrm{~mm} \mathrm{CW}$ in about $32 \mathrm{~d}$, and $9.2 \mathrm{~mm} \mathrm{CW}$ in around $50 \mathrm{~d}$, when they are very close to attain a size-refuge from larger conspecifics, even when no vegetation cover is available. Growth rates obtained in the laboratory for populations in northern Europe are substantially different. The estimated age of stage 5 juveniles, close to $5.0 \mathrm{~mm} \mathrm{CW}$ in both cases (Table 1), varied from 23 (Klein Breteler, 1975b) to 51 d (Shen, 1935). While the later seems to over-estimate development times in the field, the former is likely to be close to natural conditions, because the size of the different crab stages are markedly similar to those reported in a natural juvenile population in the Wadden Sea (Klein
Breteler, 1975a). If so, absolute growth rate during this critical juvenile phase is longer in the southern population at the Ria de Aveiro, not shorter as anticipated. Because C. maenas is a cold-temperate species, it is possible that optimal growth patterns are attained at temperature conditions prevailing in the North Sea, at the centre of its native geographic range.

\section{Role of the funding source}

Fundação para a Ciência e Tecnologia did not have any role in the design of the study, in the collection, analysis, and interpretation of data, in the writing of the report, nor in the decision to submit the paper for publication.

\section{Disclosure statement}

The authors are not aware of any actual or potential conflict of interest that may have inappropriately influenced the work in any way. MJA participated in the design of the study, and performed most of field work, data analysis and writing of the manuscript. JIGG participated in the design of the study and field work. AAVF helped in the last stage of data analysis and in the review of the manuscript. HQ is the principal investigator of the ProRecruit project and participated in the design of the study, data analysis and manuscript review.

\section{Acknowledgements}

We wish to thank Susana Oliveira, Sónia Vieira, Ângela Rico Rico and Debora Soares, as well as several undergraduate students of the Departamento de Biologia for assistance during field and laboratory work. MJA was supported by Fundação para a Ciência e Tecnologia (FCT) through a Ph D grant (SFRH/BD/6843/2001). This study is part of the 'ProRecruit - shelf processes controlling recruitment to littoral populations in an eastern oceanic boundary using barnacles and crabs as models' research project, also funded by FCT (POCTI/1999/BSE/ 36663). Financial support was allocated by FCT under the Community Support Framework III, Operational Programme Science, Technology and Innovation. [RH]

\section{References}

Airoldi, L., Beck, M.A.W., 2007. Loss, status and trends for coastal marine habitats of Europe. Oceanport. Mar. Biol. 45, 345-405.

Almeida, M.J., Queiroga, H., 2003. Physical forcing of onshore transport of crab megalopae in the northern Portuguese upwelling system. Estuary. Coast. Shelf Sci. $57,1091-1102$.

Almeida, M.J., Flores, A.A.V., Queiroga, H., 2008. Effect of crab size and habitat type on the locomotory activity of juvenile shore crabs, Carcinus maenas. Estuary. Coast. Shelf Sci. 80, 509-516.

ap Rheinallt, T., 1986. Size selection by the crab Liocarcinus puber feeding on mussels Mytilus edulis and on shore crabs Carcinus maenas: the importance of mechanical factors. Mar. Ecol. Prog. Ser. 29, 45-53.

Bailey, K.M., Houde, E.D., 1989. Predation on eggs and larvae of marine fishes and the recruitment problem. Adv. Mar. Biol. 25, 1-83.

Beck, M., 1995. Size-specific shelter limitation in stone crabs: a test of the demographic bottleneck hypothesis. Ecology 76, 968-980.

Bhattacharya, C.G., 1967. A simple method of resolution of a distribution into Gaussian components. Biometrics 23, 115-135.

Broekhuysen, G.J., 1936. On the development, growth and distribution of Carcinus maenas Arch. Neerl. Zool. 2, 257-399.

Cameron, B., Metaxas, A., 2005. Invasive green crab, Carcinus maenas, on the Atlantic coast and in the Bras d'Or Lakes of Nova Scotia, Canada: larval supply and recruitment. J. Mar. Biol. Assoc. U. K. 85, 847-855.

Casariego, A.M., Schwindt, E., Iribarne, O., 2004. Evidence of habitat structuregenerated bottleneck in the recruitment process of the SW Atlantic crab Cyrtograpsus angulatus. Mar. Biol. 145, 259-264.

Coelho, H.S., Neves, R.J.J., White, M., Leitão, P.C., Santos, A.J., 2002. A model for ocean circulation in the Iberian coast. J. Mar. Syst. 32, 153-179.

Davis, J.L.D., Young-Williams, A.C., Hines, A.H., Zmora, O., 2004. Comparing two types of internal tags in juvenile blue crabs. Fish. Res. 67, 265-274.

Dias, J.M., Lopes, J.F., Dekeyser, I., 2003. A numerical model system application to the study of the transport properties in Ria de Aveiro Lagoon. Ocean Dyn. 3 (53), 220-231. 
Flores, A.A.V., Negreiros-Fransozo, M.L., 1999. On the population biology of the mottled shore crab Pachygrapsus transversus (Gibbesm 1850) (Brachyura, Grapsidae) in a subtropical area. Bull. Mar. Sci. 65, 59-73.

Flores, A.A.V., Saraiva, J., Paula, J., 2002. Sexual maturity, reproductive cycles, and juvenile recruitment of Perisesarma guttatum (Brachyura, Sesarmidae) at Ponta Rasa mangrove swamp, Inhaca Island, Mozambique. J. Crust. Biol. 22, 143-156.

Fukui, Y., 1988. Comparative studies on the life history of the grapsid crabs (Crustacea, Brachyura) inhabiting intertidal cobble and boulder shores. Publ. Seto Mar. Biol. Lab. 33, 121-162.

Hartnoll, R.G., 1982. Growth. Pp. 111-196 In D.E., Bliss, ed.-in-chief. The Biology of Crustacea. Vol. 2. L.G., Abele, ed. Embryology, Morphology and Genetics. Academic Press, New York.

Hartnoll, R.G., 2001. Growth in Crustacea - twenty years on. Hydrobiologia 449, 111-201.

Hedvall, O., Moksnes, P.O., Pihl, L., 1998. Active habitat selection by megalopae and juvenile shore crabs Carcinus maenas: a laboratory study in an annular flume. Hydrobiologia 376, 89-100.

Holt, J.T., Proctor, R., 2003. The role of advection in determining the temperature structure of the Irish Sea. J. Phys. Oceanport. 11, 2288-2306.

Irlandi, E.A., Ambrose, W.G., Orlando, B.A., 1995. Landscape ecology and the marine environment: how spatial configuration of seagrass habitat influences growth and survival of the bay scallop. Oikos 72, 307-313.

Klein Breteler, W.C.M., 1975a. Growth and moulting of juvenile shore crabs, Carcinus maenas, in a natural population. Neth. J. Sea Res. 9, 86-99.

Klein Breteler, W.C.M., 1975b. Food consumption, growth and energy metabolism of juvenile shore crabs. Neth. J. Sea Res. 9, 255-272.

Moksnes, P.-O., 2002. The relative importance of habitat specific settlement, predation and juvenile dispersal for distribution and abundance of young juvenile shore crabs Carcinus maenas. J. Exp. Mar. Biol. Ecol. 271, 41-73.

Moksnes, P.-O., 2004a. Interference competition for space in nursery habitats: densitydependent effects on growth and dispersal in juvenile shore crabs Carcinus maenas. Mar. Ecol. Prog. Ser. 281, 181-191.

Moksnes, P.-O., 2004b. Self-regulating mechanisms in cannibalistic populations of juvenile shore crabs Carcinus maenas. Ecology 85, 1343-1354.

Moksnes, P.-O., Pihl, L., van Montfrans, J., 1998. Predation on postlarvae and juveniles of the shore crab Carcinus maenas: importance of shelter, size and cannibalism. Mar. Ecol. Prog. Ser. 166, 211-225.

Moksnes, P.-O., Hedvall, O., Reinvald, T., 2003. Settlement behavior in shore crabs: why do postlarvae emigrate from nursery areas? Mar. Ecol. Prog. Ser. 250, 215-230.
Otto, L., Zimmerman, J.T.F., Furnes, G.K., Mork, M., Saertre, R., Becker, G., 1990. Review of the physical oceanography of the North Sea. Neth. J. Sea Res. 26, 161-238.

Paradis, A.R., Pepin, P., Brown, J.A., 1996. Vulnerability of fish eggs and larvae to predation: review of the influence of the relative size of prey and predator. Can. J. Fish. Aquat. Sci. 53, 1226-1235.

Paula, J., Silva, I.C., Francisco, S.M., Flores, A.A.V., 2006. The use of artificial benthic collectors for assessment of spatial patterns of settlement of megalopae. Hydrobiologia 557, 69-77.

Perkins-Visser, E., Wolcott, T.G., Wolcott, D.L., 1996. Nursery role of seagrass beds: enhanced growth of juvenile blue crabs (Callinectes sapidus Rathbun). J. Exp. Mar. Biol. Ecol. 198, 155-173.

Queiroga, H., Almeida, M.J., Alpuim, T., Flores, A.A.V., Francisco, S., Gonzalez-Gordillo, I., Miranda, A.I., Silva, I., Paula, J., 2006. Tide and wind control of megalopal supply to estuarine crab populations on the Portuguese west coast. Mar. Ecol. Prog. Ser. 307, 21-36.

Quinn, G.P., Keough, M.J., 2002. Experimental Design and Data Analysis for Biologists. Cambridge University Press, Cambridge.

Rangeley, R.W., Thomas, M.L.H., 1987. Predatory behavior of juvenile shore crab Carcinus maenas (L.). J. Exp. Mar. Biol. Ecol. 108, 191-197.

Roman, J., Palumbi, S.R., 2004. A global invader at home: population structure of the green crab, Carcinus maenas, in Europe. Mol. Ecol. 13, 2891-2898.

Scharf, F.S., Buckel, J.A., Juanes, F., Conover, D.O., 1998. Predation by juvenile piscivorous bluefish (Pomatomus sltatrix): the influence of prey to predator size ratio and prey type on predator capture success and prey profitability. Can. J. Fish. Aquat. Sci. 55, 1695-1703.

Shen, C.J., 1935. An investigation of the post-larval development of the shore crab Carcinus maenas with special reference to secondary sexual characters. Proc. zool. Soc. Lond. 1, 1-33.

Silva, I.C., Dinis, A.M., Francisco, S.M., Flores, A.A.V., Paula, J., 2006. Longitudinal distribution and lateral pattern of megalopal settlement and juvenile recruitment of Carcinus maenas (L.) (Brachyura, Portunidae) in the Mira River Estuary, Portugal. Estuary. Coast Shelf Sci 69, 179-188.

Sprung, M., 2001. Larval abundance and recruitment of Carcinus maenas L. close to its southern geographic limit: a case of match and mismatch. Hydrobiologia 449, 153-158.

Thomas, N.J., Lasiak, T.A., Naylor, E., 1981. Salinity preference behaviour in Carcinus. Mar. Behav. Physiol. 7, 277-283.

Zeng, C.S., Abello, P., Naylor, E., 1999. Endogenous tidal and semilunar moulting rhythms in early juvenile shore crabs Carcinus maenas: implications for adaptation to a high intertidal habitat. Mar. Ecol. Prog. Ser. 191, 257-266. 